\title{
Improving the Erosion and Erosion-Corrosion Properties of Precipitation Hardening Mold Steel by Plasma Nitriding
}

\author{
Hsiang-Yao Lan and Dong-Cherng Wen* \\ Department of Mechanical Engineering, China University of Science and Technology, Taipei 11581, Taiwan, R. O. China
}

\begin{abstract}
In this study plasma nitriding of precipitation hardening mold steel has been carried out at 470,500 and $530^{\circ} \mathrm{C}$ for $12 \mathrm{~h}$ in order to achieve good erosion and erosion-corrosion resistance. The microstructure, phase present and microhardness profiles of unnitrided and nitrided layers were examined. The influence of plasma nitriding on the erosion and erosion-corrosion resistance of the tested steel was investigated using a jet solid particle erosion tester and a rotated slurry erosion-corrosion tester.

The results indicate that the surface properties of the plasma nitrided layers in terms of hardness, erosion wear, and erosion-corrosion resistance are highly dependent on nitriding temperature, and all three plasma surface treatments can significantly improve the surface hardness and effective enhance their erosion resistance under dry erosion. The erosion-corrosion resistance in $20 \mathrm{mass} \% \mathrm{SiC}$ particles/3.5\% NaCl slurry can be effectively improved 48,65 and $68 \%$ by plasma nitrided at 470,500 and $530^{\circ} \mathrm{C}$, respectively. The erosion rate decreases with increasing surface hardness and obeys a power function $\left(\dot{E} \propto H^{-n}\right)$ with exponent of 1.047 . However, the correlation between erosion-corrosion rate and hardness does not obey any power functions of the exponent in the range of 1-1.5 due to the complexity of the interaction between erosion and corrosion. [doi:10.2320/matertrans.M2012083]
\end{abstract}

(Received March 2, 2012; Accepted May 24, 2012; Published July 11, 2012)

Keywords: mold steel, plasma nitriding, erosion, corrosion, hardness

\section{Introduction}

The precipitation hardening tool steels have been used for fabricating plastic injection molds. One example is NAK80 mold steel developed by Daido Steel, Japan. This steel is usually supplied in the solution-treated condition, and its hardness ranges from 30 to $32 \mathrm{HRC}$. On aging at $470-530^{\circ} \mathrm{C}$ for $5 \mathrm{~h}$, the hardness ranges from 39 to 41 HRC. ${ }^{1)}$

Wear and corrosion are the common problems in plastic injection molds, especially in high production molds. Erosion wear is induced by the reinforced resins flow and corrosion attack from acids and chloride formed by the decomposition of thermoplastic (e.g., PVC) due to overheating. ${ }^{2)}$ As a result of the combined effects of erosion and corrosion, the overall wear rate of material can be greater than the sum of the rates of material loss from either of the two processes, erosion and corrosion, acting separately. The additional part in material loss is defined in terms of synergistic effect. ${ }^{3-5)}$ Under this background, it is required to try to take advantage of a certain surface engineering technique to address the problem in order to improve the erosion and erosion-corrosion resistance of the plastic injection molds.

Nitriding is a surface treatment technique used to introduce nitrogen into metallic materials to improve their surface hardness, mechanical properties, as well as wear and corrosion resistance. ${ }^{6-8)}$ Conventional gas and liquid nitriding processes are not suitable for precipitation hardening steels because the high temperature of over $550^{\circ} \mathrm{C}$ employed in these processes exceeds the aging temperature of such steels and could result in the overaging of the core. However, plasma nitriding can be carried out at temperatures lower than the aging temperature.

In the plasma nitriding process, by means of a grow discharge in a gas mixture of $\mathrm{N}_{2}$ and $\mathrm{H}_{2}$, with the temperature of the steel at the vicinity of $500^{\circ} \mathrm{C}$, nitrogen can penetrate

*Corresponding author, E-mail: dcwen@cc.cust.edu.tw the surface and diffuse into the steel. ${ }^{9)}$ Under such conditions, the structure of the nitrided layers produced on the steel surface can be subdivided into a compound layer and a diffusion layer. The compound layer consists of $\varepsilon$-nitride $\left(\mathrm{Fe}_{2-3} \mathrm{~N}\right)$ and $\gamma^{\prime}$-nitride $\left(\mathrm{Fe}_{4} \mathrm{~N}\right)$ as well as nitrides with alloying elements, while the diffusion layer consists mainly of interstitial atoms in solid solution and fine, coherent nitride precipitates when the solubility limit is reached. The diffusion layer determines the strength of the nitrided layer, as well as its fatigue strength, ${ }^{10,11)}$ while the compound layer determines the tribological characteristics and corrosion resistance. $^{12-14)}$

Several works have been published reporting a better performance of plasma nitrided precipitation hardening stainless steel in corrosion and wear conditions. ${ }^{15,16)}$ In another work, Öztürk et al. ${ }^{17)}$ reported an effectiveness of plasma nitriding conditions in improving the tribological and corrosion properties of $\mathrm{X} 36 \mathrm{CrMo} 17$ injection mold steel. Oliveira et al. ${ }^{18)}$ indicated the nitriding and aging of precipitation hardening plastic mold steel can be achieved simultaneously in the same treatment cycle and found that the corrosion resistance was enhanced after nitriding. However, for a deeper understanding of precipitation hardening tool steels the effects of plasma nitriding on erosion by solid particle and erosion-corrosion by slurry are essential, but very little work has been done on these aspects.

In the present investigation, NAK80 mold steel was DCpulsed plasma nitrided at 470,500 and $530^{\circ} \mathrm{C}$ for $12 \mathrm{~h}$. The metallurgical structures as well as microhardness profiles, erosion and erosion-corrosion resistance of the surface nitrided layer were evaluated, analyzed and discussed.

\section{Experimental Details}

Specimens were made out of NAK80 mold tool steel, (C 0.12, Si 0.26, Mn 1.43, Ni 3.18, Al 1.02, Cu 0.95, Mo 0.22 , Fe balanced all, in mass $\%$ ) and machined to 


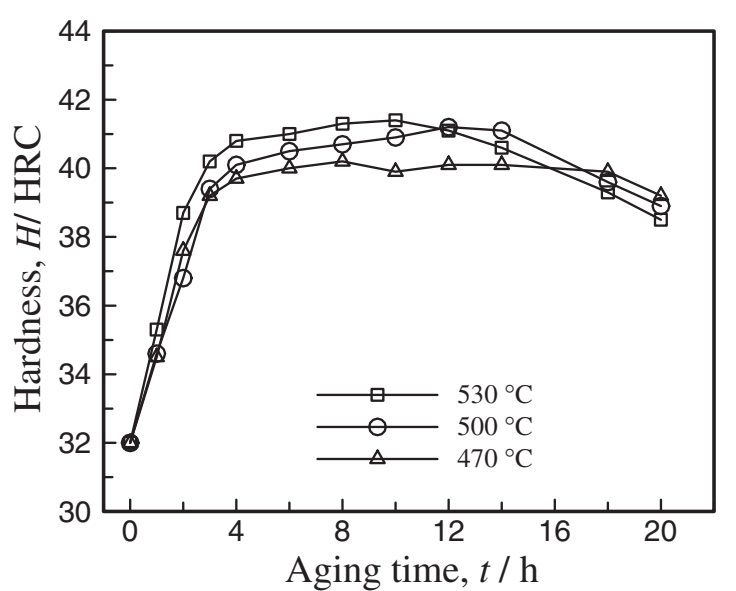

Fig. 1 Aging curves of the specimens aged at various temperatures.

$80 \times 25 \times 3 \mathrm{~mm}^{3}$ in size. The material was received in the solution and aging at $500^{\circ} \mathrm{C}$ for $5 \mathrm{~h}$ with a hardness of 40.7 HRC. This received material was left unnitrided intentionally for the purpose of comparison. These specimens were initially solubilized at $900^{\circ} \mathrm{C}$ and then aged at temperatures of 470,500 and $530^{\circ} \mathrm{C}$ for periods ranging from 1 to $20 \mathrm{~h}$ in order to draw up their aging curves, and guide the nitriding treatments. Figure 1 shows that a high hardness level was reached between 4 and $12 \mathrm{~h}$ of aging, and no signs of overaging were detected for treatment durations less than $15 \mathrm{~h}$. Therefore, the nitriding time was settled on $12 \mathrm{~h}$. Prior to the nitriding process, the specimens were polished to the same surface roughness $\left(R_{\mathrm{a}}=0.04 \mu \mathrm{m}\right)$ and cleaned in an ultrasonic bath with acetone. Plasma nitriding was carried out in an industrial nitriding facility (DC-pulsed). The specimens were sputter cleaned in an atmosphere of $80 \% \mathrm{Ar}+20 \% \mathrm{H}_{2}$ at about $250^{\circ} \mathrm{C}$ for $1 \mathrm{~h}$, to remove the oxide layers formed on their surfaces. They were then plasma nitrided in an atmosphere of $25 \% \mathrm{~N}_{2}+75 \% \mathrm{H}_{2}$ at temperatures of 470 , 500 and $530^{\circ} \mathrm{C}$ for $12 \mathrm{~h}$, with the chamber pressure maintained at $600 \mathrm{~Pa}$.

The microstructures of nitrided layers were observed by optical microscopy. The phases formed on the nitrided surface were characterized by X-ray diffraction with $\mathrm{Cu} \mathrm{K} \alpha$ radiation using a Shimadzu X-ray diffractometer (LabX XRD-6000). The microhardness of the nitrided layers was measured using a Future-Tech FM-7 automatic tester with a small load of $50 \mathrm{~g}$ for $15 \mathrm{~s}$. The erosion tests were carried out by using a typical air jet erosion test rig (ASTM G76). A jet of gas containing irregular $\mathrm{SiC}$ particles with the sizes of $255-335 \mu \mathrm{m}$ was ejected from a nozzle of $5 \mathrm{~mm}$ diameter, which then impinged on the test specimen located $30 \mathrm{~mm}$ away from the nozzle. The impingement flow speed was adjusted by air pressure and it was determined using the rotating double-disk method. ${ }^{19)}$ The eroded specimens were cleaned in acetone, dried and weighted to an accuracy of $\pm 0.01 \mathrm{mg}$, eroded in the test rig for $5 \mathrm{~min}$ and then weighted again to determine the weight loss. Additionally, these impinged particles were never used more than once.

The erosion-corrosion tests were carried out with a rotated slurry wear tester as shown in Fig. 2 of the Ref. 5) with the same electrolyte as that in corrosion test plus 20 mass $\%$ of irregular SiC particles. The rotation diameter of the specimens was $100 \mathrm{~mm}$. The bolts fixed in the holder could adjust the impact angles of solid particles. The erosion-corrosion rate $\left(\dot{E}_{\mathrm{C}}\right)$ was calculated by measuring the weight loss of specimens. The parameters employed for erosion and erosion-corrosion tests are presented in Table 1. The worn surface morphology was observed in the scanning electron microscope of JEOL JSM-5600 to study the mechanisms of erosion and erosion-corrosion wear of NAK 80 mold steel.

\section{Results and Discussion}

\subsection{Microstructure}

Optical micrographs of the unnitrided and nitrided specimens are shown in Fig. 2. These micrographs show a case hardened nitrided layer and an internal nucleus of bainite plus martensite. The nitrided surface consisted of two layers: a compound layer at the top and a nitrogen diffusion layer beneath. The thickness of the nitrided layer increased with an increase in nitriding temperature due to greater diffusivity at higher temperatures. The corresponding XRD patterns obtained from the surface of these specimens are shown in Fig. 3. The unnitrided specimen showed only $\alpha$-Fe, whereas the nitrided specimens exhibited additional peaks due to different nitrides. In the specimen treated at $470^{\circ} \mathrm{C}$, some $\varepsilon$-nitride and $\gamma^{\prime}$-nitride peaks accompanied the $\alpha$-Fe peaks. In nitriding at $500^{\circ} \mathrm{C}$, the nitrided surface layer was dominantly $\varepsilon$-nitride along with $\gamma^{\prime}$-nitride, and the amount of $\alpha$-Fe phase was much less than that in the nitriding at $470^{\circ} \mathrm{C}$. The amount of $\varepsilon$-nitride and $\gamma^{\prime}$-nitride in $530^{\circ} \mathrm{C}$ nitrided surface layer was further increased, and the amount of $\alpha$-Fe phase was decreased apparently. Therefore, the peaks of $\alpha$-Fe phase almost disappeared. Optical microscopy and XRD analysis show that the microstructure of the nitrided case is temperature depended. The intensity of the $\alpha$-Fe peaks progressively decreased, and the intensity of the nitride peaks progressively increased with increasing nitriding temperature indicating an increase in volume fraction of the nitride phase at the expense of parent $\alpha$-Fe. Our early study has been confirmed that the presence of a dense nitride layer rich in $\varepsilon$-nitride on the surface could enhance corrosion resistance. As nitride is a noble phase, formation of more nitride helps to protect the surface from corrosion attack and corrosion resistance improves with increase in nitriding temperature. ${ }^{20)}$

\subsection{Microhardness}

Figure 4 shows that the microhardness of the nitrided specimens is greater than that of the substrate material by a factor of approximately 1.6 to 1.8 . The depth of the hardened layers extends nearly 45, 140 and $200 \mu \mathrm{m}$ below the surface for the specimens nitrided at 470,500 and $530^{\circ} \mathrm{C}$, respectively. In addition, the microhardness is in graded distribution from the surface to the core of the specimens, which is beneficial to the surface mechanical properties of the specimens.

\subsection{Erosion by solid particles}

Figure 5 shows the cumulative weight losses of unnitrided and nitrided specimens versus erosion time. The unnitrided specimen exhibits the highest value of weight loss and that 

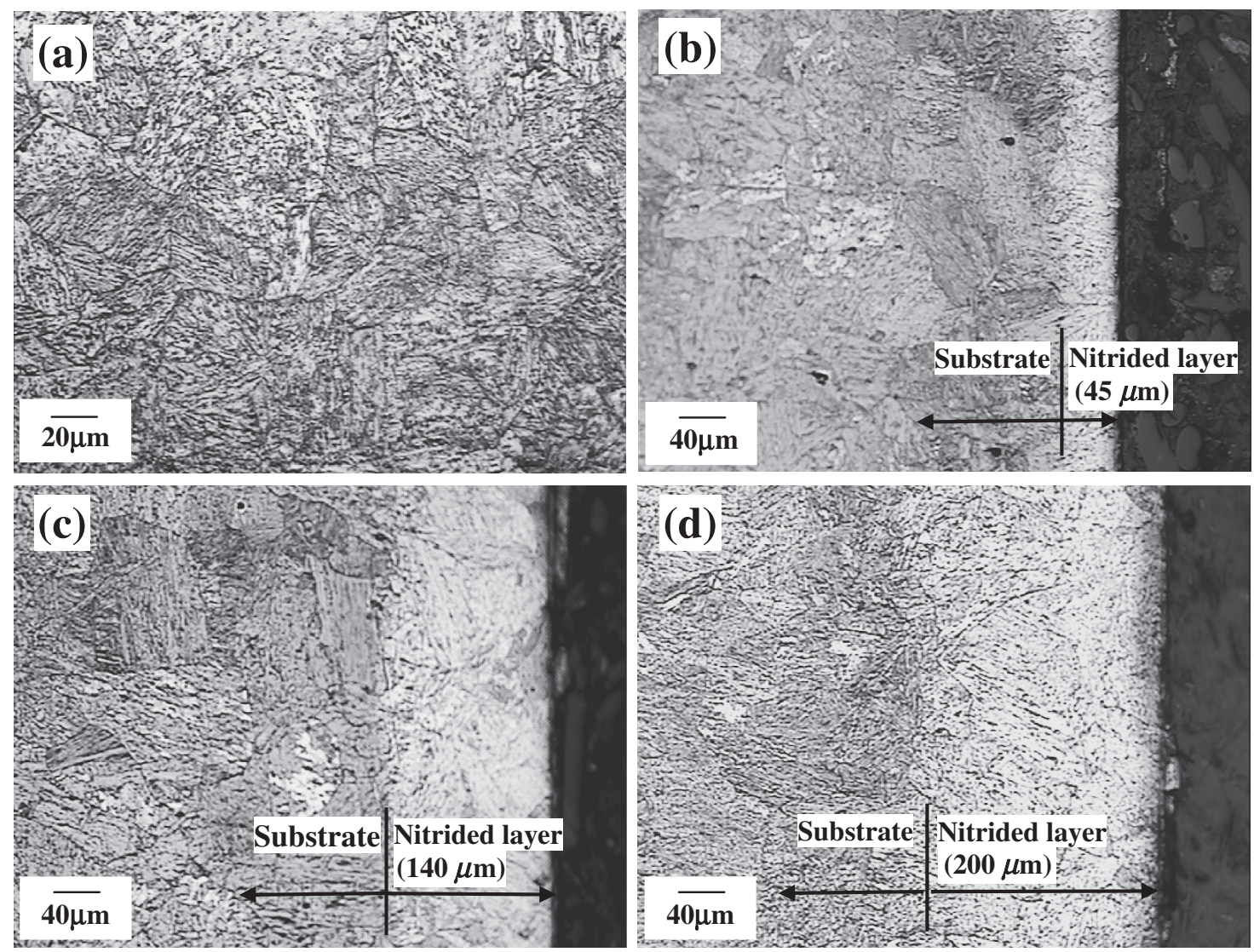

Fig. 2 Optical microscopy images of (a) unnitrided specimen, (b) nitrided at $470^{\circ} \mathrm{C}$ for $12 \mathrm{~h}$, (c) nitrided at $500^{\circ} \mathrm{C}$ for $12 \mathrm{~h}$ and (d) nitrided at $530^{\circ} \mathrm{C}$ for $12 \mathrm{~h}$

Table 1 Parameters for the erosion and erosion-corrosion tests used in this study.

\begin{tabular}{lll}
\hline \multicolumn{1}{c}{ Parameter } & \multicolumn{1}{c}{ Erosion } & \multicolumn{1}{c}{ Erosion-corrosion } \\
\hline \multirow{2}{*}{ Erodent } & $\mathrm{SiC}$, feed rate: & 20 mass $\% \mathrm{SiC}+3.5 \%$ \\
& $15 \pm 0.4 \mathrm{~g} \mathrm{~min}^{-1}$ & $\mathrm{NaCl}$ solution \\
Impact velocity, $v / \mathrm{m} \mathrm{s}^{-1}$ & 30 & 7.3 \\
Impact angle & $30^{\circ}$ & $30^{\circ}$ \\
Test duration, $t / \mathrm{min}$ & 30 & 60 \\
\hline
\end{tabular}

are found to increase linearly with increasing erosion time. This indicates that the erosion mechanism does not change noticeably, implying a steady erosion damage during the impingement processes. However, the cumulative weight losses are significantly improves with the formation of nitrided layers on the nitrided specimen surface. It is strongly believed that the diffusion zone extends the erosion process incubation period. For $470^{\circ} \mathrm{C}$ nitrided specimen, the weight loss increases linearly at a moderate slope until a turning point found at $20 \mathrm{~min}$. This feature is ascribed to the hardening effect of diffusion zone which provides a moderate resistance to erosion wear. After erosion at the time of turning point, the diffusion zone is impinged off and the base material is exposed; hence, the erosion rate is similar to that of unnitrided specimen. For 500 and $530^{\circ} \mathrm{C}$ nitrided specimens, the depth of erosion tracks are still within the diffusion zone. Consequently, steady erosion damage with lower weight losses than $470^{\circ} \mathrm{C}$ nitrided specimen is found. In

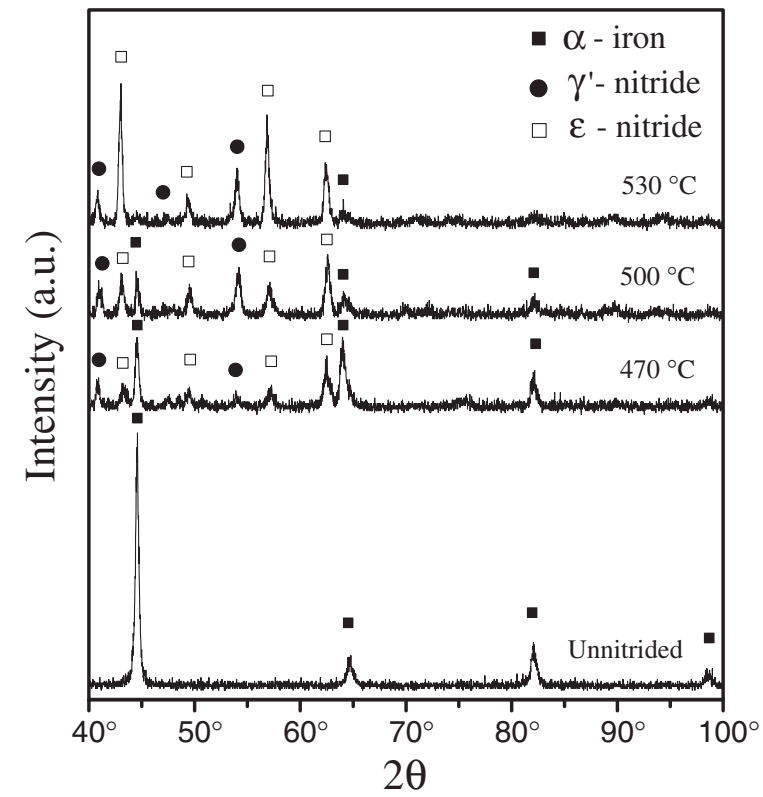

Fig. 3 XRD diffraction patterns of the unnitrided and nitrided specimens.

Fig. 5, the ratio of the weight loss in the curve to the weight of the eroding particles causing the loss (i.e., testing time $\times$ particles feed rate) was then computed as the dimensionless erosion rate $(\dot{E})$. The erosion rates are 0.205 , $0.138,0.119$ and $0.108 \mathrm{mg} \mathrm{g}^{-1}$ for the unnitrided and 470 , 500 and $530^{\circ} \mathrm{C}$ nitrided specimens, respectively. 


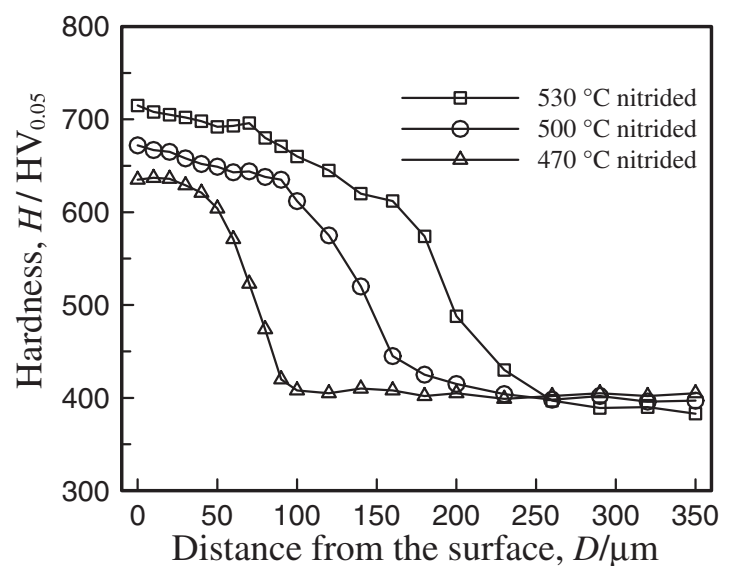

Fig. 4 Microhardess depth profiles for NAK80 mold steel nitrided for $12 \mathrm{~h}$.

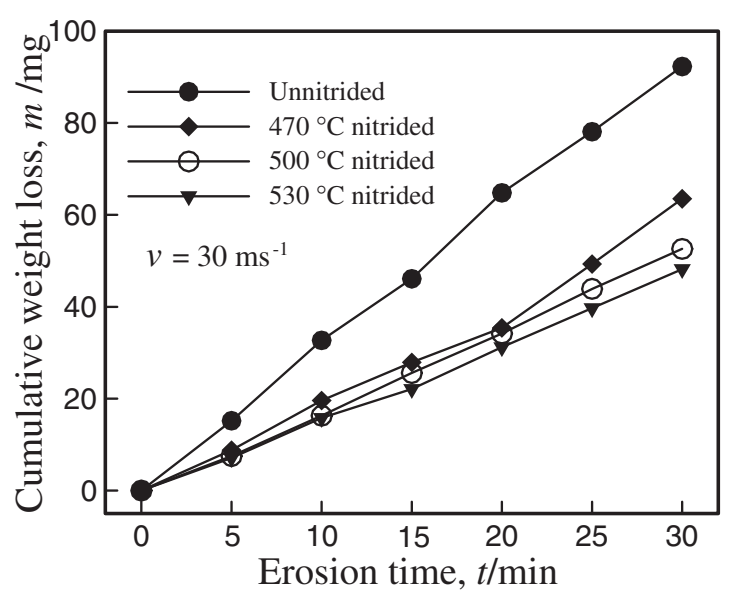

Fig. 5 Cumulative weight losses of unnitrided and nitrided specimens versus erosion time.
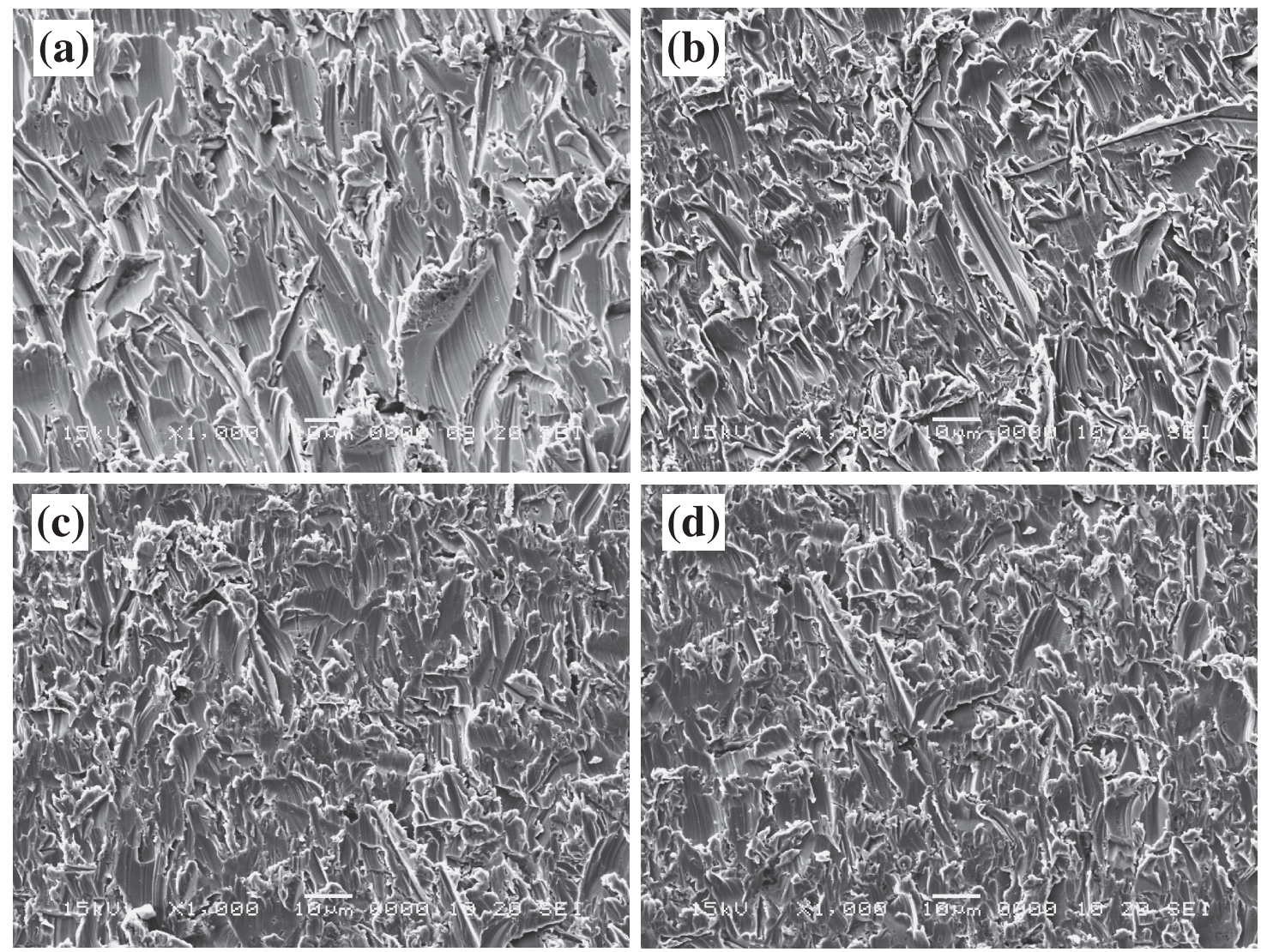

Fig. 6 Solid particle erosion morphologies of the specimens after $30 \mathrm{~min}$ impingement: (a) unnitrided, (b) $470^{\circ} \mathrm{C}$ nitrided, (c) $500^{\circ} \mathrm{C}$ nitrided and (d) $530^{\circ} \mathrm{C}$ nitrided.

Figure 6 shows the typical SEM micrographs of the eroded surfaces for the unnitrided and nitrided specimens after 30 min impingement erosion. Due to the relatively low hardness, the surface of the unnitrided specimen is severely deformed during erosion test. Obvious plough grooves and cutting lips appear in the eroded surface, and wider and deeper erosion trace could be seen in Fig. 6(a). This ploughing mechanism will have a significant material removal rate, and hence exhibit a high erosion rate. On the other hand, all the nitrided specimens exhibit considerably less erosion damage. The erosion tracks on the eroded surfaces of the nitrided specimens are found to be shallow and superficial. This is attributed to the formation of nitrided layer on the surface of the nitrided steel. However, the difference of erosion tracks between the 500 and $530^{\circ} \mathrm{C}$ nitrided specimens is not significantly confirming the change of their erosion rate only slightly. Compared with the unnitrided specimen, all the nitrided specimens exhibit milder erosion damage and lower erosion rate. The improvement of the erosion resistance for plasma nitrided NAK80 mold steel is considered as a result of combined effects of the microstructure and the high surface hardness in the nitrided 
layer. The high surface hardness can resist the plastic deformation, and reduce the plough grooves and cutting damages impacted by particles. As the nitriding temperature increases, both the surface hardness and the hardness-profile depth increase. Consequently, the erosion resistance improves with nitriding temperature.

\subsection{Erosion-corrosion behavior of slurry}

The erosion-corrosion rate for the unnitrided and nitrided specimens is compared in Fig. 7. It can be seen that the erosion-corrosion resistance in 20 mass $\% \mathrm{SiC}$ particles $/ 3.5 \%$ $\mathrm{NaCl}$ slurry can be improved 48,65 , and $68 \%$, respectively

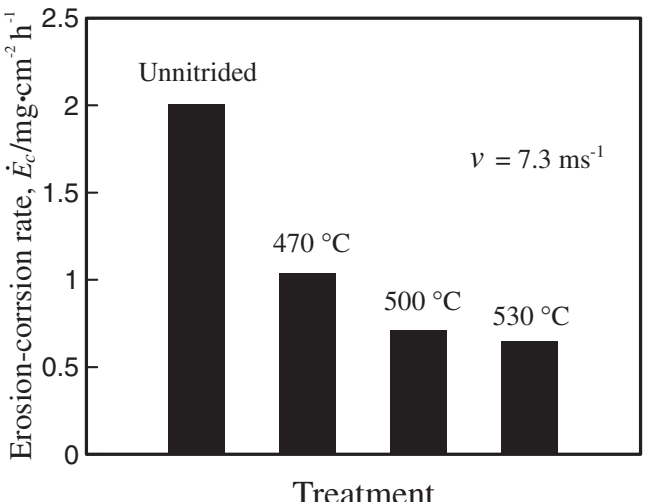

Fig. 7 The erosion-corrosion rate of the unnitrided and nitrided specimens after $60 \mathrm{~min}$. by nitriding at 470,500 and $530^{\circ} \mathrm{C}$. The nitrided specimens have higher surface hardness, better solid particle erosion resistance and undamaged passivating film, which guaranteed their better property in erosion-corrosion resistance than that of the unnitrided specimen.

The surface morphologies of the unnitrided and nitrided specimens after 60 min erosion-corrosion test are shown in Fig. 8. The unnitrided specimen corrodes most severely, and some large and deep circular pits as well as several erosion tracks can be seen on the surface (Fig. 8(a)). This can be attributed to its low hardness and hence mediocre resistance to erosion (Fig. 6(a)) combined with poor corrosion resistance leads the highest total weight loss. Both corrosion pits and erosion tracks could also be seen on the erosioncorrosion surface of the 470 and $500^{\circ} \mathrm{C}$ nitrided specimens, but the amount of erosion tracks and the size and dimension of pits were less than those of the unnitrided specimen. For the $530^{\circ} \mathrm{C}$ nitrided specimen, only mild cutting grooves are observed on the surface and there is no corrosion pits. Although the corrosion resistance of all three plasmanitriding specimens is enhanced but the depth of the nitrided layer for the $470^{\circ} \mathrm{C}$ nitrided specimen is thinner than that for high temperature $\left(500\right.$ and $\left.530^{\circ} \mathrm{C}\right)$ nitrided specimens. During the erosion-corrosion test, the thinner nitride layer could be penetrated more quickly and the protection by nitride from corrosion attack failed. Therefore, the erosioncorrosion surface of the $470^{\circ} \mathrm{C}$ nitrided specimen showed much more corrosion pits (Fig. 8(b)) while the $530^{\circ} \mathrm{C}$ nitrided specimen showed no corrosion pits (Fig. 8(d)).
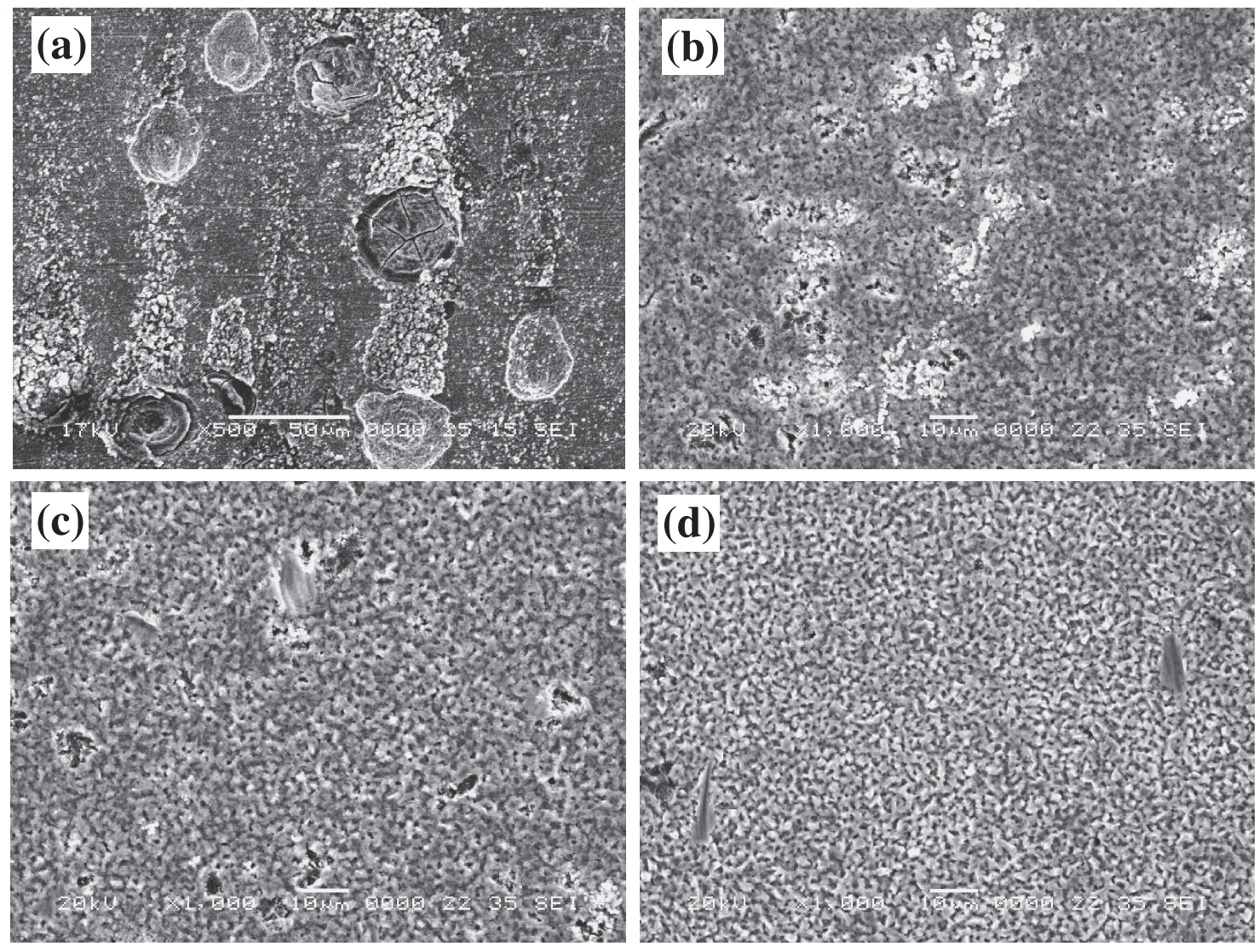

Fig. 8 Erosion-corrosion morphologies of the specimens (a) unnitrided, (b) $470^{\circ} \mathrm{C}$ nitrided, (c) $500^{\circ} \mathrm{C}$ nitrided and (d) $530^{\circ} \mathrm{C}$ nitrided. 


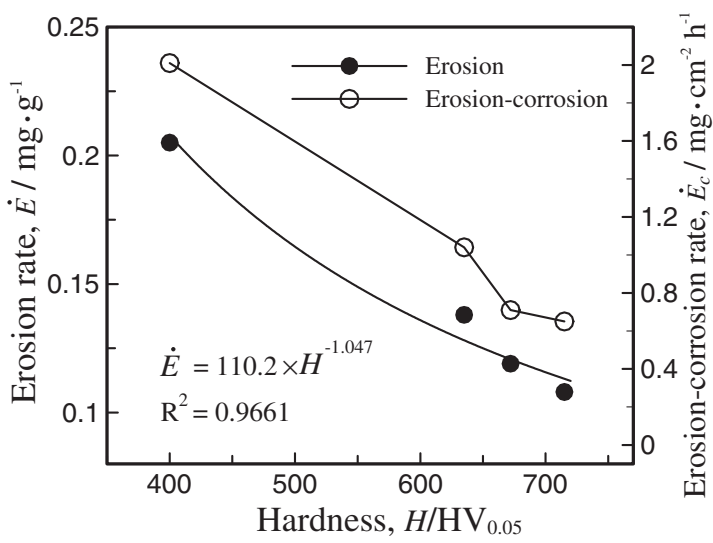

Fig. 9 Effect of surface hardness on the erosion and erosion-corrosion of unnitrided and nitrided NAK80 mold steel.

\subsection{Hardness effect}

Erosion by impact of solid particles is a mechanical process and is thus dependent on mechanical properties of the surface. For solid particle erosion, material removal occurs by two mechanisms, namely by: plastic deformation and brittle fracture. The former is surface hardness dependent whilst the latter is fracture toughness dependent. ${ }^{21)}$ In general, the softer the specimen surface, the deeper and larger are the cutting grooves. In our cases, the hardness of the impacted particles is much higher than that of the tested materials, these particles will indent the tested samples, and the relative motion will lead to the formation of groove as shown in Fig. 6. Although abrasion and erosion depend not only on hardness, but also on toughness and elastic modulus of the materials, as reporter by Zum Gahr, ${ }^{22)}$ however, our test conditions were in the high wear region according to the hardness model of Rabinowicz, ${ }^{23}$ the volume of the worn groove is proportional to the contact area of the hard particle on the soft surface. Therefore, the volume of the removed materials is equal to the volume of the groove and then the wear rate can be expressed as a function of hardness of the tested samples according to Tabor's relation. ${ }^{24)}$ Figure 9 depicts the correlation between the erosion rate and surface hardness of the tested specimens. As can be seen from Fig. 9, the erosion rate falls exponentially with the surface hardness of NAK80 mold steel. In erosion theory, ${ }^{25)}$ the relationship between the erosion rate and the hardness $(H)$ of the surface can be expressed approximately by: $\dot{E} \propto H^{-n}$. The exponent $n$ depends mainly on the impact angle and material removal mechanism. For oblique angles of incidence, material is removal by individual particles in a cutting action and $n=1$; at high impact angles debris becomes detached only after repeat deformation under cyclic plastic deformation and $n=1.5$. In Fig. 9, the erosion rate of NAK 80 mold steel obeyed the above power function $\left(R^{2}=0.9661\right)$ with the exponent $n=1.047$ confirming that the material removal during erosion is most probably via cutting.

It can be seen from Fig. 9 that the erosion-corrosion rate of NAK 80 mold steel also decreases with increasing surface hardness; however, its correlation does not obey any power functions for the exponent of 1-1.5. Because the erosioncorrosion rate depends on pure corrosion, pure erosion and more importantly the synergistic effects between erosion and corrosion. The complexity of the interaction between erosion and corrosion could possibly cause that the correlation between erosion-corrosion rate and hardness does not obey the power function.

\section{Conclusions}

(1) Plasma nitriding can be used to produce a variety of surface layer structure in NAK80 precipitation hardening mold steel, and the surface properties of the layers in terms of hardness, erosion wear and erosion-corrosion resistance are highly dependent on nitriding temperature.

(2) The erosion-corrosion resistance of NAK 80 mold steel in a 20 mass $\% \mathrm{SiC}$ particles $/ 3.5 \% \mathrm{NaCl}$ slurry can be improved 48, 65 and $68 \%$, respectively by plasma nitrided at 470,500 and $530^{\circ} \mathrm{C}$.

(3) The erosion rate of NAK80 mold steel decreases with increasing surface hardness and obeys a power function $\left(\dot{E} \propto H^{-n}\right)$. The exponent is about 1.047 for the erosion confirming that the material removal is most probably via cutting. However, the correlation between erosioncorrosion rate and hardness does not obey the power function because the interactions between erosion and corrosion are complex.

\section{REFERENCES}

1) http://www.daido.co.jp/english/products/tool/plasticmold.html

2) L. L. Sheir, R. A. Jarman and G. T. Burstein: Corrosion, Corrosion Control, (Butterworth-Heinemann, Oxford, 1994).

3) T. Zhang and D. L. Li: J. Mater. Sci. 36 (2001) 3479-3486.

4) M. Matsumura, Y. Oka, H. Hiura and M. Yano: ISIJ Int. 31 (1991) 168176.

5) D. C. Wen: J. Mater. Sci. 44 (2009) 6363-6371.

6) Q. F. Peng: Wear 129 (1989) 195-203.

7) U. Huchel, S. Bramers, J. Crummenauer, S. Dressler and S. Kinkel: Surf. Coat. Technol. 76-77 (1995) 211-217.

8) C. V. Franco, F. G. Mittelstadt, J. L. R. Muzart, A. R. Souza and L. P. Cardoso: J. Mater. Sci. 31 (1995) 431-435.

9) K. T. Rie: Surf. Coat. Technol. 112 (1999) 56-62.

10) S. Li and R. R. Manory: J. Mater. Sci. 34 (1999) 1045-1049.

11) J. Sjöström and J. Bergström: J. Mater. Process. Technol. 153-154 (2004) 1089-1096.

12) M. Terčelj, A. Smolej, P. Fajfar and R. Turk: Tribol. Int. 40 (2007) 374 384.

13) P. Psyllaki, G. Kefalonikas, G. Pantazopoulos, S. Antoniou and J. Sideris: Surf. Coat. Technol. 162 (2003) 67-78.

14) M. B. Karamis and E. Gercekcioglu: Wear 243 (2000) 76-84.

15) M. Esfandiari and H. Dong: Surf. Coat. Technol. 202 (2007) 466-478.

16) G.-j. Li, J. Wang, C. Li, Q. Peng, J. Gao and B.-1. Shen: Nucl. Instrum. Methods Phys. Res. B 266 (2008) 1964-1970.

17) O. Öztürk, O. Onmuș and D. L. Williamson: Surf. Coat. Technol. 196 (2005) 333-340.

18) S. D. Oliveira, A. P. Tschiptschin and C. E. Pinedo: Mater. Des. 28 (2007) 1714-1718.

19) A. W. Ruff and L. K. Ives: Wear 35 (1975) 195-199.

20) D. C. Wen: Appl. Surf. Sci. 256 (2009) 797-804.

21) M. D. Bermudez, F. J. Carrion, G. Martinze-Nicolas and R. Lopez: Wear 258 (2005) 693-700.

22) K. H. Zum Gahr: Microstructure and Wear of Materials, Tribology, series no 10, (Elsevier, Amsterdam, 1987) pp. 531-553.

23) E. Rabinowicz: Friction and Wear of Materials, (John Wiley and Sons, New York, 1965).

24) D. Tabor: The Hardness of Metals, (Clarendon Press, Oxford, 1951).

25) I. M. Hutchings: Tribology: Friction and Wear of Engineering Materials, (Edward Arnold, London, 1992). 